\title{
How timing of stem girdling affects needle xylem structure in Scots pine
}

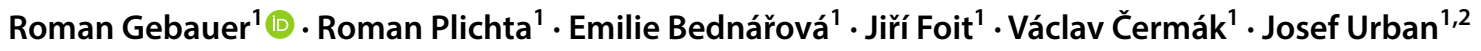

Received: 23 September 2016 / Revised: 12 October 2017 / Accepted: 21 November 2017

c) Springer-Verlag GmbH Germany, part of Springer Nature 2017

\begin{abstract}
While needles represent a proportionally large fraction of whole-plant hydraulic resistance, no studies to date have investigated how source-sink disturbances affect needle xylem structure. In this study, we evaluated structural changes in xylem in current-year needles of Scots pine 227 and 411 days after stem girdling (hereafter referred to as DAG). Maximum and minimum tracheid lumen diameters and therefore also the size of tracheid lumen areas increased in needles 227 DAG compared to control needles. In contrast, tracheid dimensions were similar in needles $411 \mathrm{DAG}$ as in the control needles, but smaller xylem area and lower number of tracheids resulted in the lower theoretical needle hydraulic conductivity of those needles. Several needle xylem parameters were intercorrelated in both control and girdled trees. These observed changes provide a new understanding of the processes that occur following a source-sink disturbance. Considering anatomical parameters such as the number of tracheids, tracheid dimension, or needle xylem area, which are rarely described in physiological studies, could be helpful, for example, in understanding to tree hydraulic systems or for modeling gas exchange. Finally, empirical equations were developed to calculate needle theoretical hydraulic conductivity and the number of tracheids in needles using an easily measurable parameter of needle xylem area.
\end{abstract}

Keywords Carbohydrates $\cdot$ Hydraulic architecture $\cdot$ Needle anatomy $\cdot$ Needle growth $\cdot$ Pinus sylvestris $\cdot$ Tracheids $\cdot$ Xylem transport

\section{Introduction}

Vascular bundles in tracheophytes are composed mostly of xylem and phloem, the two principal long-distance transport pathways. Xylem serves as a conducting tissue primarily for transferring water and nutrients from the soil to leaves, whereas phloem serves as the pathway for transporting photosynthates, genes, and hormones from leaves or storage

Communicated by Judy Simon.

Electronic supplementary material The online version of this article (https://doi.org/10.1007/s10342-017-1090-z) contains supplementary material, which is available to authorized users.

Roman Gebauer

roman.gebauer@mendelu.cz

1 Faculty of Forestry and Wood Technology, Mendel University in Brno, Zemědělská 3, 61300 Brno, Czech Republic

2 Siberian Federal University, Svobodnyj Prospekt 79, Krasnoyarsk, Russia organs (source) to regions of active growth or storage organs (sink). The loss of secondary phloem due to wounding can, therefore, be detrimental to overall tree vitality (Aulen 1991; Rawlinson et al. 2004). Numerous studies have reported that the manipulation of source-sink relationships by stem girdling can effectively kill trees, although the time taken for trees to die can vary between species (Negreros-Castillo and Hall 1994; Wilson and Gartner 2002; Taylor and Cooper 2002; Pariona et al. 2003).

Stem girdling has been shown to lead to an accumulation of non-structural carbohydrates (NSC) in leaves and stems above the girdle (Myers et al. 1999; Murakami et al. 2008) and to the gradual depletion of carbohydrate reserves in roots and, subsequently, to starvation (Weaver and McCune 1959). At the same time, removal of the root sink generally results in decreased stomatal conductance (López et al. 2015), in an accumulation of abscisic acid in leaves (Setter et al. 1980; Williams et al. 2000) and to a consequential decline in photosynthesis through end-product inhibition (Myers et al. 1999; Urban and Alphonsout 2007; Murakami et al. 2008). Lower transpiration in girdled trees due to stomatal closure 
leads to a reduction in leaf hydraulic conductance (Domec and Pruyn 2008; Sellin et al. 2013) and to an increase in leaf water potential (Williams et al. 2000).

Girdling affects annual ring width, the duration of cambial growth, as well as the start time and duration of latewood production (Wilson and Gartner 2002; Domec and Pruyn 2008; Maunoury-Danger et al. 2010). As a consequence, the hydraulic properties of wood produced after girdling differ to those of unwounded trees (Cernusak and Marshall 2001; Domec and Pruyn 2008). However, no studies have assessed the effects of stem girdling on leaf and needle xylem structure. Leaves and needles typically comprise a substantially smaller proportion of the path length in plant vascular systems than stems, yet they represent a disproportionately large fraction (> 30\%) of whole-plant hydraulic resistance (Yang and Tyree 1994; Nardini and Salleo 2000). The current consensus is that the hydraulic resistance of leaf/ needle xylem is about equal to that of extra-xylem pathways (Nardini et al. 2005; Sack and Holbrook 2006). Thus, needle xylem structure is a key component for understanding tree hydraulic architecture. The other interesting question is how long-term phloem transport disruption influences the correlation between needle structural parameters given that anatomical traits can differ dramatically from needle to needle along a canopy (Gebauer et al. 2015). These features are likely regulated by an interplay between endogenous and environmental factors (Bongard-Pierce et al. 1996). For example, leaf lamina growth requires coordination between the epidermis and the mesophyll layers (Kawade et al. 2013). Thus, leaf size is expected to be a complex trait (Zhao et al. 2011) and any disturbance such as the accumulation of abscisic acid and carbohydrates above the girdle ultimately interferes with normal leaf development.

The current study focused on Scots pine (Pinus sylvestris L.) as it is the most widely distributed pine species and one of the most important timber species in Eurasia (Poyatos et al. 2007). The aim of this study was to increase our knowledge of the effects of stem girdling on needle xylem structure adaptation of Scots pine trees 8 and 14 months after girdling (hereafter referred to as 227 and 411 DAG-days after girdling, respectively). We tested the following three hypotheses: (1) girdling will change the correlations between needle structural parameters as a result of sink-source disturbance; (2) xylem area, tracheid dimension, the number of tracheids and theoretical hydraulic conductivity will increase as a result of carbohydrate accumulation in needles 227 DAG; and (3) the opposite will be observed 411 DAG, as root starvation will lead to decreased sap flow and water shortage in the needles.

\section{Materials and methods}

\section{Study site and experimental design}

The study site is an even-aged mixed coniferous/deciduous forest stand located in the Training Forest Enterprise Masaryk Forest in Krrtiny (with site coordinates: $49^{\circ} 15^{\prime} 39^{\prime \prime} \mathrm{N}, 16^{\circ} 36^{\prime} 20^{\prime \prime} \mathrm{E}$ ), an organizational unit of Mendel University in Brno (Czech Republic). The altitude of the site is $340 \mathrm{~m}$ a.s.l. Long-term average annual air temperature and precipitation are $8.7^{\circ} \mathrm{C}$ and $490 \mathrm{~mm}$, respectively, based on daily weather data from 1961 to 1990 from the nearest meteorological station at Brno-Tuřany. At this location, the mean air temperature for the whole of 2014 was $11.3{ }^{\circ} \mathrm{C}$ and the sum of precipitation was $609 \mathrm{~mm}$. The stand was planted in 1928, and the abundance of Scots pine (Pinus sylvestris L.) is higher than $70 \%$. The soil type is mesotrophic Cambisol. Two experimental plots (each measuring $2500 \mathrm{~m}^{2}$, situated $200 \mathrm{~m}$ apart) were established within the stand in March 2013. Eleven co-dominant Scots pine trees, all 86 years old, with breast height diameters ranging from 29 to $36 \mathrm{~cm}$ were selected from each experimental plot for detailed analysis (22 trees in total). On each experimental plot, three trees were selected as controls, four trees were girdled on July 15 , 2013, and additional four trees were girdled 6 months later on January 15, 2014 (Fig. 1). Girdling consisted in removing 7-10-cm-wide bands of bark (periderm, cortex, secondary phloem and cambium) from around the entire stem at the height of $1.3 \mathrm{~m}$ above the soil surface, thus exposing the outer surface of the sapwood and disrupting phloem transport. Stem tissue regeneration was regularly checked to avoid phloem sap flow reconnection. The girdled area was completely covered with resin at the end of experiment.

\section{Sap flow and phenology}

Sap flow was monitored from April 1 to August 30, 2014 in all experimental trees (Fig. 1), using EMS 51 sap flow meters (EMS Brno, Czech Republic) on the basis of the trunk heat balance principle (Čermák et al. 1973; Kučera et al. 1977). Sap flow sensors were located above the girth. To account for variability in tree size, sap flow was standardized per unit of a circumference and expressed in $\mathrm{kg} \mathrm{cm}^{-1}$ of the tree circumference. Soil water potential was measured at three depths $(15,50$, and $90 \mathrm{~cm})$ from April 1 to August 30, 2014, with gypsum blocks (GB1, Delmhorst, USA) connected to a MicroLog SP3 datalogger (EMS Brno, Czech Republic). Phenological events (bud burst, beginning of flowering and end of flowering) were observed for each tree in the year 2014. 
Fig. 1 Diagram illustrating individual actions (bottom axis labels and black vertical bars) applied to control or girdled trees during experiment duration (upper axis labels). Two groups of trees were girdled separately (period after girdling in gray) on July 15,2013 , and January 15, 2014. Sap flow and soil water potential were measured from April 1 to August 30, 2014. Needle samples for nonstructural carbohydrates (NSC) analysis were taken on April 1 and August 30, 2014. Needle samples for anatomical analysis were taken on August 30, 2014. $D A G$ days after girdling

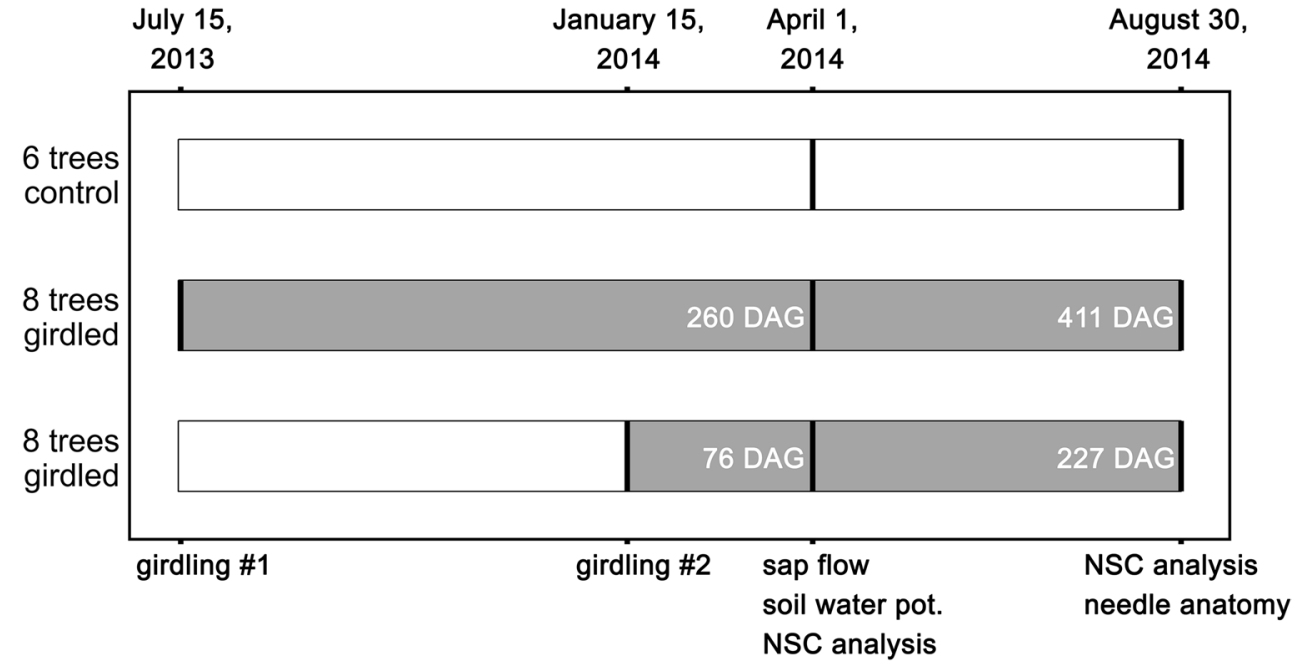

needles per tree), and a second needle for measuring the projected needle surface area.

\section{Needle xylem structure}

Hand-cut cross sections for anatomical analyses were taken at the needle base and treated with phloroglucinol and hydrochloric acid staining to show lignin in red. The stained sections were examined under an Olympus BX51 light microscope (Olympus Corporation, Tokyo, Japan) at a magnifications of up to $400 \times$, and photographed using a Canon EOS 1100D digital camera (Canon Inc., Tokyo, Japan) connected to a computer by QuickPhoto Micro 3.1 software (Promicra, Prague, Czech Republic). Tracheid lumens were manually colored using Adobe Photoshop 9.0 (Adobe Systems, San Jose, CA, USA) (Fig. 2). The phloem area $\left(A_{\mathrm{p}}\right)$, xylem area $\left(A_{\mathrm{x}}\right)$, mean tracheid lumen area $\left(A_{\text {lum }}\right)$, and maximum and minimum lumen diameters ( $d_{\max }$ and $d_{\min }$, respectively) were measured using ImageJ software (The University of Texas Health Science Centre, San Antonio, TX, USA). Tracheid roundness $\left(T_{\mathrm{r}}\right)$ was defined as the ratio of $d_{\max }$ to $d_{\min }$, with a ratio of 1 denoting tracheids with a perfectly round cross section and larger ratios denoting more or less ellipsoidal tracheids. We also quantified the number of tracheids per needle $\left(T_{\text {num }}\right)$, total lumen area per needle $\left(A_{\mathrm{n} \_l u m}\right)$, and xylem to phloem area ratio $\left(R_{\mathrm{a}}\right)$.

\section{Theoretical hydraulic conductivity}

The tracheid theoretical hydraulic conductivity $\left(K_{\text {th } \_}\right)$was calculated according to the Hagen-Poiseuille law (Eq. 1) (Cruiziat et al. 2002). Since the tracheid lumen is not usually circular, we applied a minor modification to the formula, as recommended by Martre et al. (2000) (Eq. 2). 


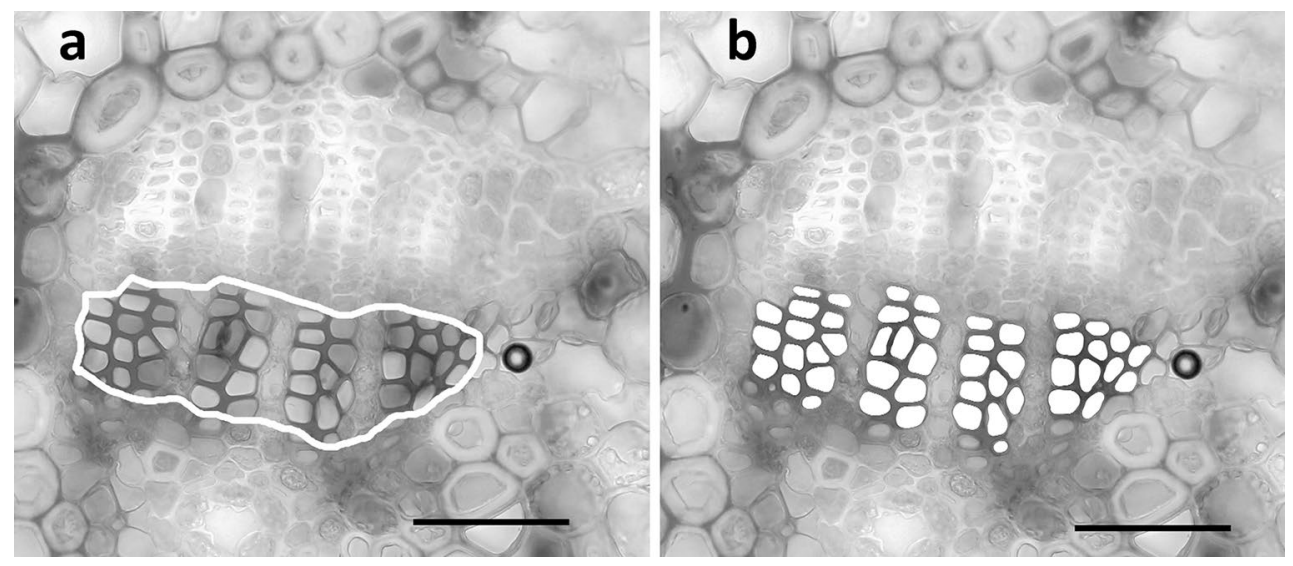

Fig. 2 Detailed micrograph of the vascular cylinder of a Scots pine needle. Xylem area is shown encircled by the white line (a). Tracheid lumens were filled in with white using Adobe Photoshop 9.0 (b) and measured using ImageJ software. The black bar represents $50 \mu \mathrm{m}$

$K_{\text {th_t }}=\frac{\pi}{8 \eta} r_{\text {lum }}^{4}$

$r_{\text {lum }}^{4}=\frac{d_{\max }^{3} d_{\text {min }}^{3}}{8 d_{\text {max }}^{2}+8 d_{\min }^{2}}$

where $r_{\text {lum }}$ is the tracheid lumen radius and $\eta$ is the viscosity of water at $20{ }^{\circ} \mathrm{C}\left(1.002 \mathrm{e}^{-9} \mathrm{MPa} s\right)$.

The needle theoretical hydraulic conductivity $\left(K_{\text {th_n }}\right)$ was calculated as the sum of all $K_{\text {th_t }}$ per needle. Then, the xylem-specific hydraulic conductivity $\left(K_{\text {s_xylem }}\right)$ was estimated as $K_{\text {th } \_ \text {n }}$ divided by $A_{\mathrm{x}}$, and needle-specific hydraulic conductivity $\left(K_{\text {s_leaf }}\right)$ was estimated as $K_{\text {th_n }}$ divided by the projected needle surface area. To determine the projected needle surface area, 20 fresh needles per tree were scanned. Further, all $K_{\text {th_t }}$ in each needle were sorted in descending order and cumulatively summed (starting from the largest tracheid) until the sum equals to $95 \%$ of $K_{\text {th_n }}$. The mean diameter $\left(D_{95}\right)$ was then calculated for this subset of tracheids, as recommended by Tyree and Zimmermann (2002).

\section{Statistical analysis}

A linear mixed effect model (LME) with restricted maximum likelihood method (REML) was used, where individual trees were specified as a random effect (Zuur et al. 2009). The simple linear model was used for $K_{\text {s_leaf }}$. Subsequently, Tukey's honest significant difference (HSD) test was used to differentiate between treatments (significance level 0.05). We used the open source $\mathrm{R}$ software environment ( $\mathrm{R}$ Core Team 2015) for all statistical analysis. LME values were fitted using the lme function in the nonlinear mixed effect (NLME) library, and Tukey's test was performed using the generalized linear hypothesis test (GLHT) function in the multcomp library. Final empirical equations were derived using a generalized linear model with gamma distribution and identity link since variance was increasing with the predictor. Mean values are presented with \pm standard errors unless stated otherwise.

All acronyms, abbreviations, and symbols are defined in Table 1.

\section{Results}

\section{Sap flow and phenology}

Sap flow was highest in the control trees and lower in both groups of girdled trees $(p<0.001)$. There was no difference between the trees 227 DAG and 411 DAG ( $p=0.147)$. Sap flow accumulated within the period April 1 to August 30, 2014 was $23.5 \pm 2.6,11.3 \pm 5.3$, and $7.2 \pm 3.8 \mathrm{~kg} \mathrm{~cm}^{-1}$ of tree circumference in the control trees, trees $227 \mathrm{DAG}$ and trees 411 DAG, respectively.

There were no phenological differences between girdled and control trees. Budburst occurred between April 23 and 24 , flowering started between May 7 and 9, and flowering ended between May 23 and 26 .

\section{Carbohydrates}

The NSC concentration in needles varied between the two sampling days, in April and in August (Fig. 3). In April, insoluble NSC concentrations were higher in both groups of girdled trees than for the control trees $(p<0.001)$ (Fig. 3a), while soluble NSC concentrations were the same for all three groups of trees ( $p=0.19)$ (Fig. 3a). In August, needles 227 DAG had more insoluble NSC $(p<0.001)$ than needles 411 DAG and control trees, which did not differ from each other $(p=0.55)$ (Fig. 3b). The concentrations of 
Table 1 Overview of the needle parameters, their abbreviations, definitions, and units used throughout this study

\begin{tabular}{lll}
\hline Parameter & Explanation & Unit \\
\hline$A_{\text {lum }}$ & Tracheid lumen area & $\mu \mathrm{m}^{2}$ \\
$A_{\mathrm{n} \_l u m}$ & Tracheid lumen area of needle & $\mu \mathrm{m}^{2}$ \\
$A_{\mathrm{p}}$ & Phloem area of needle & $\mu \mathrm{m}^{2}$ \\
$A_{\mathrm{x}}$ & Xylem area of needle & $\mu \mathrm{m}^{2}$ \\
$d_{\text {max }}$ & Maximum tracheid lumen diameter & $\mu \mathrm{m}$ \\
$d_{\text {min }}$ & Minimum tracheid lumen diameter & $\mu \mathrm{m}$ \\
$D_{95}$ & Mean diameter of all tracheids that account for $95 \%$ of the & $\mu \mathrm{m}$ \\
& $K_{\text {th_n }}$ & \\
$K_{\text {th_n }}$ & Theoretical needle hydraulic conductivity & $\mathrm{kg} \mathrm{m} \mathrm{s}^{-1} \mathrm{MPa}^{-1}$ \\
$K_{\mathrm{s} \_ \text {leaf }}$ & Theoretical leaf-specific hydraulic conductivity & $\mathrm{kg} \mathrm{m}^{-1} \mathrm{~s}^{-1} \mathrm{MPa}^{-1}$ \\
$K_{\mathrm{s} \_ \text {xylem }}$ & Theoretical xylem-specific hydraulic conductivity & $\mathrm{kg} \mathrm{m}^{-1} \mathrm{~s}^{-1} \mathrm{MPa}^{-1}$ \\
$R_{\mathrm{a}}$ & Ratio $A_{\mathrm{x}}$ to $A_{\mathrm{p}}$ & - \\
$T_{\text {num }}$ & Number of tracheids per needle & - \\
$T_{\mathrm{r}}$ & Tracheid roundness $\left(d_{\text {max }} / d_{\text {min }}\right)$ & - \\
\hline
\end{tabular}

Fig. 3 Non-structural carbohydrate concentrations (NSC; soluble-black column; starch-gray column) for April 1 and August 30, 2014. Vertical bars indicate standard errors. Asterisks indicate a significant difference from control
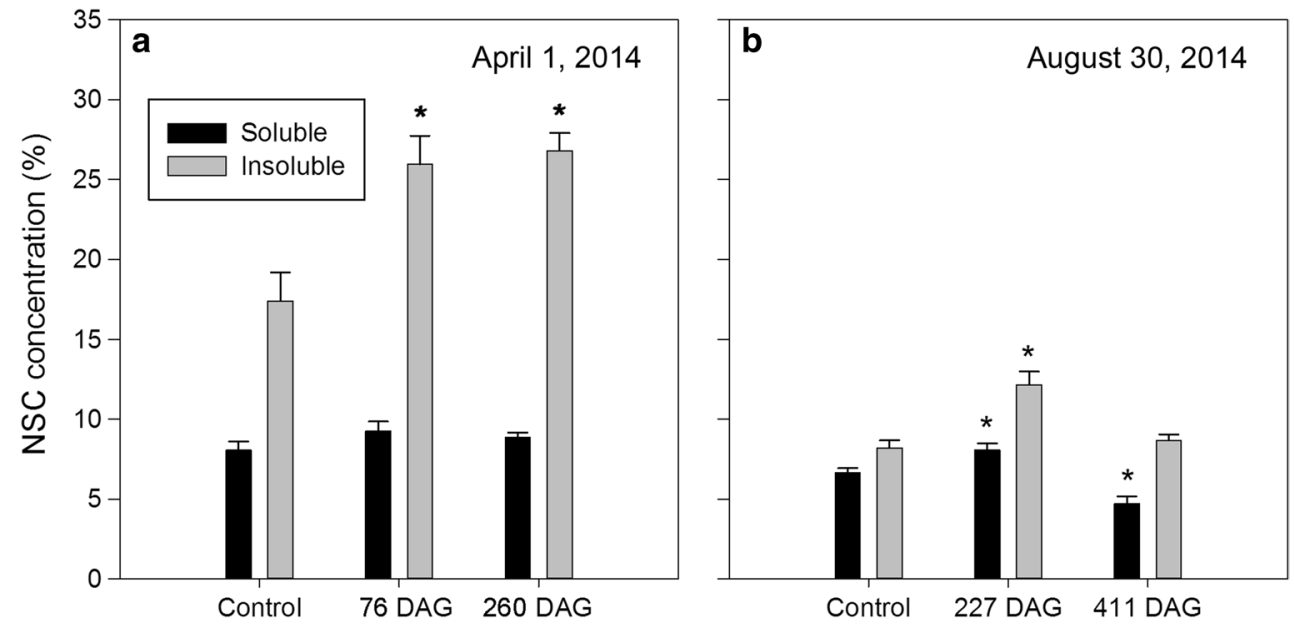

soluble NSC were higher in needles 227 DAG $(p<0.001)$ and lower in needles 441 DAG $(p<0.001)$ compared to the control trees (Fig. 3b).

\section{Correlation between needle parameters}

Several needle parameters were correlated with each other in control needles (16 out of 45 possible correlations), in needles 227 DAG (12 correlations), and needles 411 DAG (22 correlations) (Fig. 4). From all observed correlations, 11 were identical for all three treatments. The strongest relationships were found for $K_{\mathrm{th} \_\mathrm{n}}, d_{\mathrm{min}}$, and $K_{\text {s_xylem }}$ (Fig. 4). The less well-correlated parameters were $T_{\mathrm{r}}$ and $R_{\mathrm{a}}$. In practical terms, the correlations between $A_{\mathrm{x}}$ and $K_{\mathrm{th} \_\mathrm{n}}$ and between $A_{\mathrm{x}}$ and $T_{\text {num }}$ in all treatments allowed us to devise empirical equations to calculate the more difficult-to-measure parameters $K_{\text {th_n }}$ and $T_{\text {num }}$ from the more easily measured $A_{\mathrm{x}}$ (Fig. 5).

\section{Needle xylem structure 227 DAG}

On average, $A_{\text {lum }}, d_{\text {max }}$, and $d_{\text {min }}$ increased in needles 227 DAG by 8,9 , and $16 \%$, respectively, compared to the control needles (Fig. 6a, d, e). It resulted in as much as 9\% higher $\mathrm{D}_{95}$ in needles 227 DAG than in the control needles (Fig. 6f). The increased tracheid dimensions in needles 227 DAG also corresponded to $27 \%$ higher $K_{\text {th_n }}$ and $23 \%$ higher $K_{\text {s_xylem }}$ compared to the control needles (Fig. $6 \mathrm{~g}, \mathrm{~h}$ ). While $A_{\mathrm{n} \_l u m}$, $A_{\mathrm{x}}$, and $K_{\text {s_leaf }}$ in needles 227 DAG were also higher than in the control needles (Fig. 6b, c, h), these differences were not significant (Table 2). Other studied needle parameters $\left(R_{\mathrm{a}}\right.$, $T_{\text {num }}$, and $T_{\mathrm{r}}$ ) 227 DAG showed similar levels to those for the control needles (Fig. 6j, k, 1 and Table 2).

\section{Needle xylem structure 411 DAG}

Patterns of needle xylem structure and development in needles 227 DAG were different to those observed in needles 
Fig. 4 Correlation matrices for needle parameters of control trees (upper panels), trees 227 days after girdling (DAG; middle panels), and trees 411 DAG (lower panels). Pearson's correlation coefficient (numbers in boxes) and significance level (asterisks in boxes) are distinguished in background color: black box $(r \geq 0.6 ; p<0.05)$; white box $(r<0.6 ; p>0.05)$. $P$ values are denoted as $p \leq 0.001$ $(* * *), p \leq 0.01(* *), p \leq 0.05$

(*), $p \geq 0.05(-)$

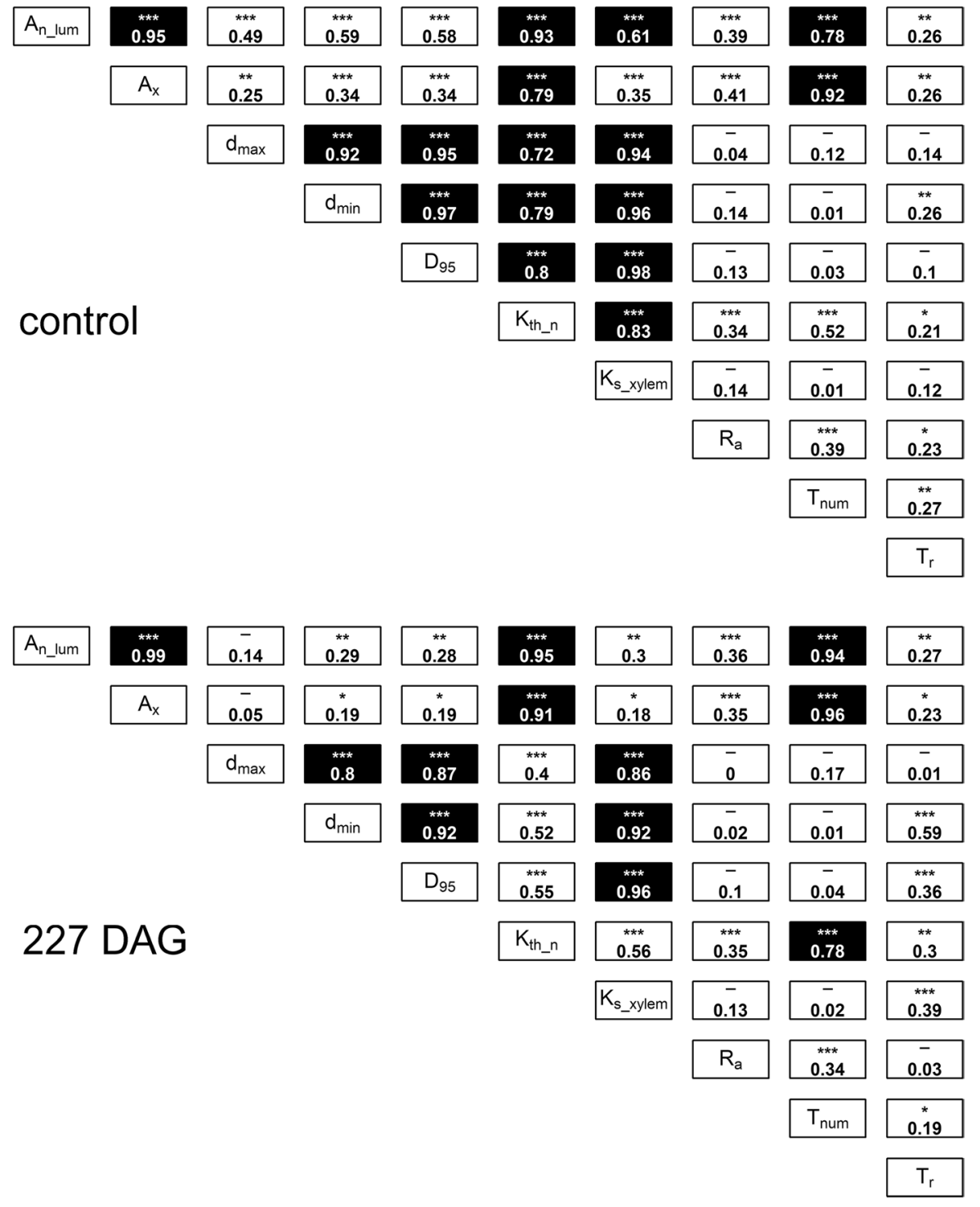

\begin{tabular}{|c|c|c|c|c|c|c|c|c|c|}
\hline$A_{n \_l u m}$ & $\begin{array}{c}* * * \\
0.99\end{array}$ & $\begin{array}{l}* \star * \\
0.4\end{array}$ & $\begin{array}{c}* \star * \\
0.77\end{array}$ & $\begin{array}{l}* * * \\
0.71\end{array}$ & $\begin{array}{l}* * * \\
0.97\end{array}$ & $\begin{array}{c}* * * \\
0.73\end{array}$ & $\overline{0}$ & $\begin{array}{l}* * * \\
0.95\end{array}$ & $\begin{array}{r}\star * * \\
0.59 \\
\end{array}$ \\
\hline & $A_{x}$ & $\begin{array}{c}* * * \\
0.33\end{array}$ & $\begin{array}{c}* * * * \\
0.72\end{array}$ & $\begin{array}{l}* * * \\
0.66\end{array}$ & $\begin{array}{l}* * * * \\
0.94\end{array}$ & $\begin{array}{c}* * * \\
0.66\end{array}$ & $\begin{array}{c}- \\
0.03 \\
\end{array}$ & $\begin{array}{c}* * * \\
0.97\end{array}$ & $\begin{array}{r}* * * \\
0.59 \\
\end{array}$ \\
\hline & & $\mathrm{d}_{\max }$ & $\begin{array}{c}* * * \\
0.68\end{array}$ & $\begin{array}{c}* * * \\
0.81\end{array}$ & $\begin{array}{l}* \star * * \\
0.5\end{array}$ & $\begin{array}{c}* * * \\
0.78\end{array}$ & $\begin{array}{l}\text { *** } \\
0.29\end{array}$ & $\overline{0}$ & $\overline{0.09}$ \\
\hline & & & $\mathrm{d}_{\min }$ & $\begin{array}{c}* * * \\
0.96\end{array}$ & $\begin{array}{c}* * * \\
0.85\end{array}$ & $\begin{array}{c}* * * \\
0.96\end{array}$ & $\begin{array}{c}* * * \\
0.34 \\
\end{array}$ & $\begin{array}{c}* * * \\
0.58 \\
\end{array}$ & $\begin{array}{c}* * * \\
0.65\end{array}$ \\
\hline & & & & $D_{95}$ & $\begin{array}{c}* * * \\
0.81\end{array}$ & $\begin{array}{c}* * * \\
0.98\end{array}$ & $\begin{array}{l}* * * * \\
0.34\end{array}$ & $\begin{array}{l}* * * \\
0.5\end{array}$ & $\begin{array}{c}* * * \\
0.46\end{array}$ \\
\hline 411 & & & & & $K_{\text {th_n }}$ & $\begin{array}{c}* * * \\
0.83\end{array}$ & $\overline{0}$ & $\begin{array}{c}* * * \\
0.85\end{array}$ & $\begin{array}{c}* \star * \\
0.58\end{array}$ \\
\hline & & & & & & $\mathrm{K}_{\mathrm{S}_{\text {_xylem }}}$ & $\begin{array}{l}* * * \\
0.35\end{array}$ & $\begin{array}{l}* * * \\
0.5 \\
\end{array}$ & $\begin{array}{c}* * * \\
0.49 \\
\end{array}$ \\
\hline & & & & & & & $\mathrm{R}_{\mathrm{a}}$ & $\overline{0} \overline{03}$ & ${ }_{0.2}^{*}$ \\
\hline & & & & & & & & $T_{\text {num }}$ & $\begin{array}{c}* * * \\
0.58\end{array}$ \\
\hline & & & & & & & & & $T_{r}$ \\
\hline
\end{tabular}



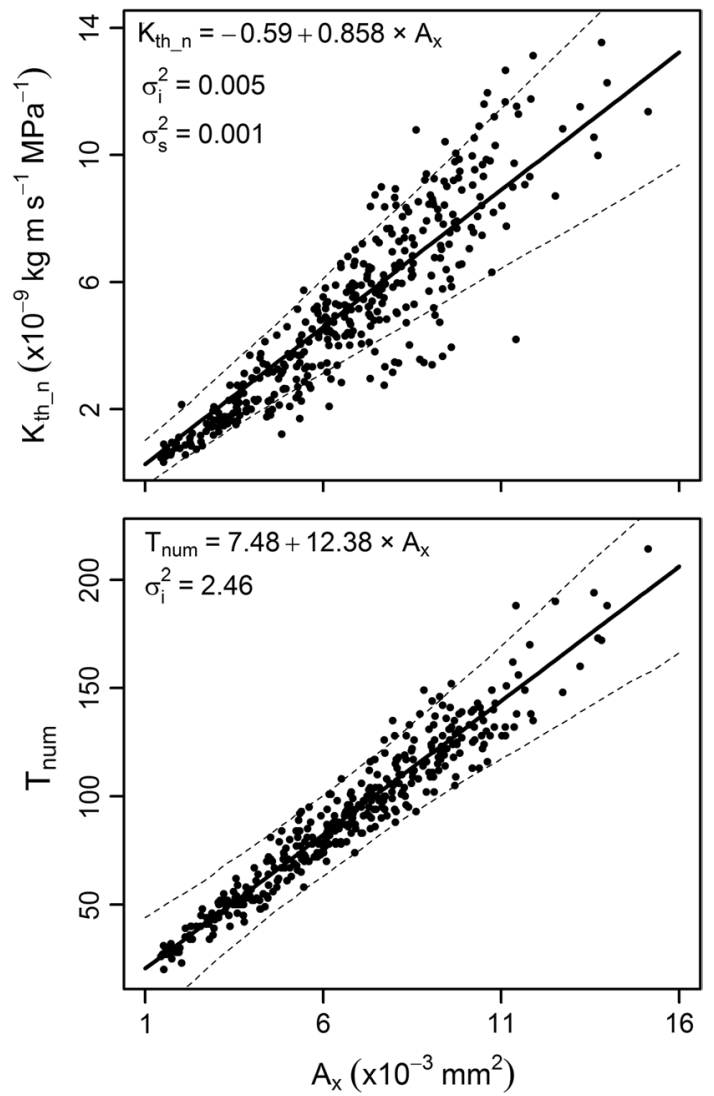

Fig. 5 Linear regressions of theoretical needle hydraulic conductivity $\left(K_{\text {th_n }}\right)$ and a number of tracheids $\left(T_{\text {num }}\right)$ per needle with needle xylem area $\left(A_{\mathrm{x}}\right)$. The $p$ value was lower than 0.001 for each regression line

411 DAG (Fig. 6). Tracheid dimensions, $K_{\text {s-leaf }}$, and $K_{\text {s_xylem }}$ were similar in both 411 DAG and control needles (Fig. 6d, e, h, 1 and Table 2); however, $K_{\text {th_n }}$ was as much as $39 \%$ lower than in control needles (Fig. $6 \mathrm{~g}$ and Table 2). Lower $K_{\text {th_n }}$ can be explained by the $36 \%$ lower level of $T_{\text {num }}$ in needles 411 DAG (Fig. 6k), which also corresponded with lower $A_{\mathrm{n} \_ \text {lum }}$ and $A_{\mathrm{x}}$ (both by $36 \%$ ) in needles 411 DAG (Fig. 6b, c). In contrast to their levels, $227 \mathrm{DAG}, R_{\mathrm{a}}$, and $T_{\mathrm{r}}$ increased in needles 411 DAG when compared to the control needles (Fig. 6j, 1 and Table 2). This indicated that decreased $d_{\min }$ in needles 411 DAG caused tracheids to be more ellipsoidal.

\section{Discussion}

For both ecologists and physiologists, foliar morphology and anatomy are important for understanding the physiology of the whole tree (Yan et al. 2012). The control of leaf size, and, by extension, leaf form, is a principle way in which plants adapt to environmental conditions. These features are likely regulated by the interplay between several endogenous and environmental factors (Bongard-Pierce et al. 1996). Our study on Scots pine clearly shows that stem girdling in this species triggers significant structural changes in needle xylem, which corresponds to previously measured morphological and physiological changes observed after stem girdling in several tree species (e.g., Myers et al. 1999; Rivas et al. 2007; Urban and Alphonsout 2007; Murakami et al. 2008). We found evidence of complex relationships related to growth, as several needle xylem parameters correlated with one or more of other parameters (we found 11 correlations between needle parameters common for all three variants of experiment out of 45 possible combinations). Only $T_{\mathrm{r}}$ and $R_{\mathrm{a}}$ were developed independently of the other studied parameters and did not correlate with anything else. The number of intercorrelated parameters decreased in trees 227 DAG to 12 , but increased in trees 411 DAG to 21 as compared to 16 in control trees. These findings support our first hypothesis that change in the physiology will affect on the correlation among needle xylem anatomical traits. We expected to find strong correlations between $K_{\mathrm{th} \_\mathrm{n}}$ and $d_{\max }$, $d_{\min }$ and $T_{\text {num }}$, as $K_{\text {th_n }}$ should theoretically be more or less dependent on these parameters. However, such a correlation was weak in both the control needles (weak correlation with $T_{\text {num }}$ ) and the needles of girdled trees (weak correlations with $d_{\max }$ or $d_{\min }$ ). This resulted especially from weak correlations of $T_{\text {num }}$ with the dimensions of tracheids $\left(d_{\min }, d_{\max }, D_{95}\right)$, even though one could expect a negative correlation here. Such a weak correlation suggests that cell expansion takes place, at least to some extent, aside from the development of a number of tracheids, as some tracheids could already be developed in dormant buds; however, their dimensions are thereafter affected by the conditions of the following growing season. Nevertheless, the strong correlation of $T_{\text {num }}$ and $K_{\text {th_n }}$ with $A_{\mathrm{x}}$ facilitated the development of empirical equations in the present study, which enabled $K_{\text {th_n }}$ and $T_{\text {num }}$ to be calculated from the more easily measured $A_{\mathrm{x}}$.

Several needle xylem parameters were influenced by girdling 227 DAG. Most importantly, tracheid diameters increased which brought along increased values of $K_{\text {th } \_n}$ and $K_{\text {s } x y l e m}$ as hydraulic conductivity increases with the fourth power of the conduit diameter, according to Hagen-Poiseuille equation. In spite of increased needle hydraulic conductance, the sap flow decreased. It indicated reduced stomatal conductance (Meinzer et al. 1997; Phillips and Oren 1998; Ewers et al. 2007; Kučera et al. 2017), which was also observed in other studies on girdled trees (De Schepper and Steppe 2011; López et al. 2015). The reason for stomatal closure after stem girdling could be the feedback inhibition of photosynthesis due to the accumulation of NSC in leaves (Fig. 2) (López et al. 2015), which leads to a more favorable leaf water status (Williams et al. 2000; Sellin et al. 2013). Such conditions could have lead to the increase in tracheid dimensions 227 DAG, as cell expansion is positively affected by higher water potential (Dale 1988), and a higher NSC 

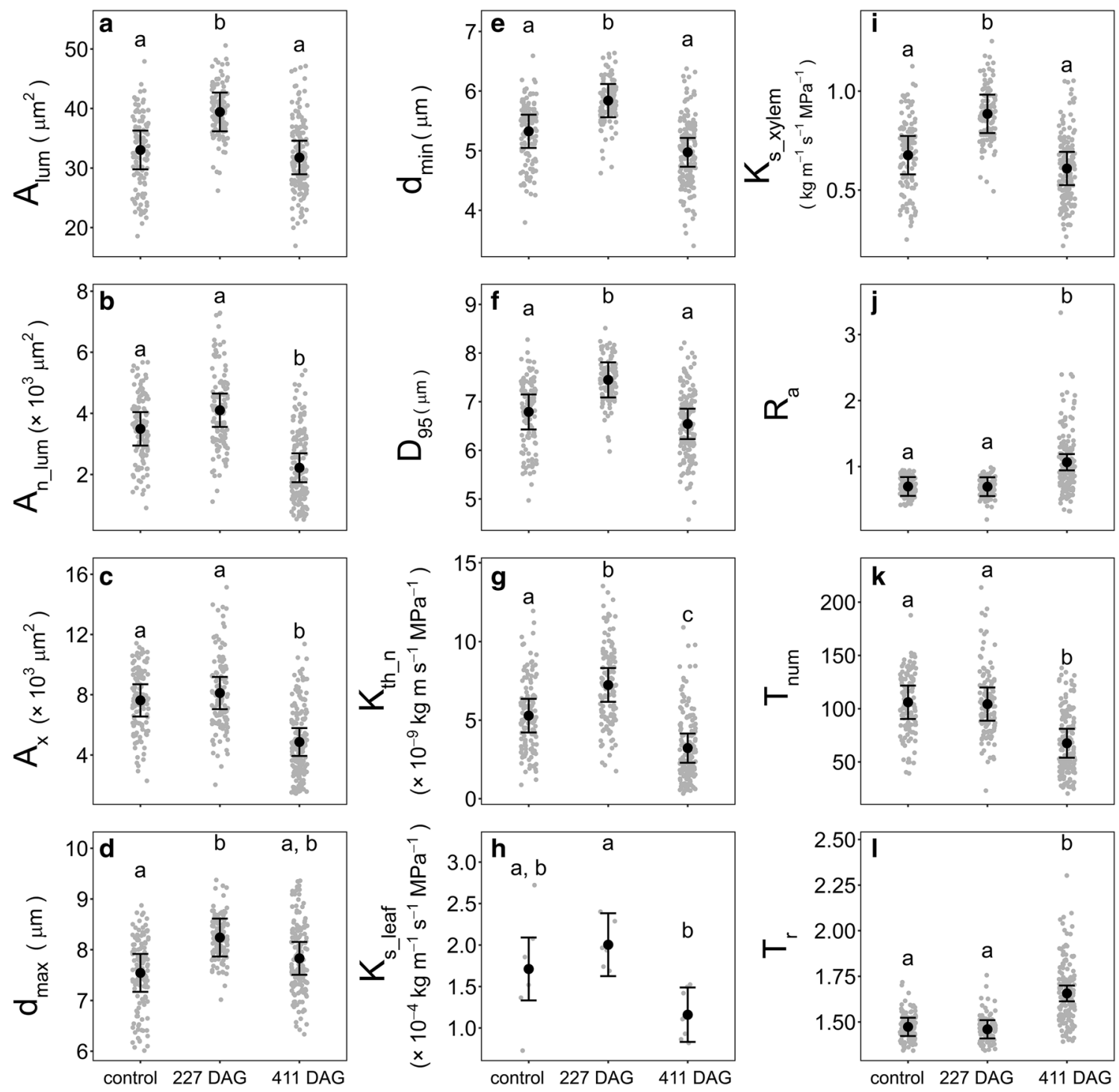

Fig. 6 Means of needle parameters from Scots pine control needles and needles 227 and 411 days after girdling (DAG). Vertical bars are 95\% confidence intervals derived from the appropriate model. Param- eters that are significantly different at the $5 \%$ significance level are indicated by different letters

roots are gradually depleted of their carbohydrate reserves causing them to suffer from starvation (Weaver and McCune 1959). This scenario led to very low transpiration rates in trees 411 DAG compared to control trees and consequently to the death of the whole tree (Negreros-Castillo and Hall 1994; Pariona et al. 2003), which in our study, was observed to occur in all 411 DAG trees. It is difficult to assess the contribution of plant water and carbon balance to tree death as they are interdependent (McDowell 2011; Hartmann et al. 2013a). For example, Hartmann et al. (2013a) showed that drought killed trees much faster than carbon starvation; however, they also showed that drought caused phloem pathway disturbance leading to carbon starvation in roots, similar to girdling (Hartmann et al. 2013b). Poor leaf development and 
Table $2 P$ values from the Tukey's honest significant difference (HSD) test showing the probability of differences in parameters between control needles and needles 227 or 411 days after girdling (DAG) and between needles 227 and 411 DAG

\begin{tabular}{llll}
\hline Parameter & $P$ value & & \\
\cline { 2 - 4 } & Control $\times 227$ & Control $\times 411$ & 227 \\
& DAG & DAG & DAG $\times 411$ \\
& & & DAG \\
\hline$A_{\text {lum }}$ & $\mathbf{0 . 0 1}$ & 0.81 & $<\mathbf{0 . 0 0 1}$ \\
$A_{\text {n_lum }}$ & 0.22 & $<\mathbf{0 . 0 0 1}$ & $<\mathbf{0 . 0 0 1}$ \\
$A_{\text {x }}$ & 0.77 & $<\mathbf{0 . 0 0 1}$ & $<\mathbf{0 . 0 0 1}$ \\
$d_{\text {max }}$ & $\mathbf{0 . 0 2}$ & 0.44 & $<\mathbf{0 . 0 0 1}$ \\
$d_{\text {min }}$ & $\mathbf{0 . 0 2}$ & 0.11 & $<\mathbf{0 . 0 0 1}$ \\
$D_{95}$ & $\mathbf{0 . 0 2}$ & 0.52 & $<\mathbf{0 . 0 0 1}$ \\
$K_{\text {th_n }}$ & $\mathbf{0 . 0 2}$ & $\mathbf{0 . 0 0 6}$ & $<\mathbf{0 . 0 0 1}$ \\
$K_{\text {s_leaf }}$ & 0.50 & 0.08 & $<\mathbf{0 . 0 0 1}$ \\
$K_{\text {s_xylem }}$ & $\mathbf{0 . 0 0 4}$ & 0.51 & $<\mathbf{0 . 0 0 1}$ \\
$R_{\text {a }}$ & 0.99 & $<\mathbf{0 . 0 0 1}$ & $<\mathbf{0 . 0 0 1}$ \\
$T_{\text {r }}$ & 0.92 & $<\mathbf{0 . 0 0 1}$ & $<\mathbf{0 . 0 0 1}$ \\
$T_{\text {num }}$ & 0.99 & $<\mathbf{0 . 0 0 1}$ & $<\mathbf{0 . 0 0 1}$ \\
\hline
\end{tabular}

Significantly different parameters $(P$ values $<0.05)$ are highlighted in boldface

smaller leaf size were previously observed in three deciduous tree species during the second growing season following stem girdling (Baldwin 1934). This corresponds to our observations of decreased $A_{\mathrm{x}}$ levels in Scots pine needles $411 \mathrm{DAG}$, which were as much as $36 \%$ lower than $A_{\mathrm{x}}$ levels in the control needles. Interestingly, the tracheid dimensions were nearly the same as for control trees. However, a significant reduction in the number of tracheids in needles $\left(T_{\text {num }}\right)$ was observed $411 \mathrm{DAG}$. Such a reduction resulted in lower $K_{\text {th_n }}$. On the other hand, both $K_{\text {s_leaf }}$ and $K_{\text {s_xylem }} 411$ DAG were similar to control needles, as there are several close interconnections between needle parameters. The decrease in $K_{\text {th_n }}$ was coupled with a reduction in $A_{\mathrm{x}}$ (used for $K_{\text {s_xylem }}$ calculation) and also with a reduction in the projected needle surface area (used for $K_{\text {s_leaf }}$ calculation) leading to only marginal changes in $K_{\text {s_xylem }}$ and $K_{\text {s_leaf. }}$. These observations partly support the third hypothesis and confirm that several leaf parameters are closely linked to each other, as previously proposed by Sack and Holbrook (2006).

In general, $K_{\text {s_leaf }}$ is a parameter representing the capacity of a shoot to supply water to distal parts (i.e., leaves) (hydraulic sufficiency; Tyree and Ewers 1991), and $K_{\text {s_xylem }_{1}}$ is a useful parameter for gauging the hydraulic efficiency of a particular tree segment (Cruiziat et al. 2002). According to the studies above, the needle hydraulic sufficiency observed here did not depend on how much time passed after stem girdling, in contrast to needle hydraulic efficiency, which increased in needles 227 DAG. It should also be noted that calculated values of hydraulic conductivity can differ from actual measured values. Measured hydraulic conductivity, for example, was found to be only $30-50 \%$ of the calculated conductivity in conifers due to the high fraction of pits and pit membranes hydraulic resistance (Froux et al. 2002; Sperry et al. 2006). Nevertheless, for tracheid diameters below $20 \mu \mathrm{m}$, which was the case here, lumen accounts for a much greater proportion of hydraulic resistance than pits (Hacke et al. 2005). Thus, in our study, the calculated hydraulic conductivity could have been close to measured values. A new and promising technique was recently developed which enables direct measurements of needle hydraulic conductivity using the flow meter technique (Charra-Vaskou and Mayr 2011; Charra-Vaskou et al. 2012). With this innovation, the relationship between calculated and measured needle hydraulic conductivity can be studied in future research to evaluate resistance partitioning within needles.

In addition to stem girdling, other factors such as physical site characteristics, climate conditions, tree age, nutrition, and overall tree health also play important roles in needle development. The $d_{\max }$ in our trees was $\sim 7.8 \mu \mathrm{m}$, which was $4 \mu \mathrm{m}$ less than in Scots pine trees growing in optimal conditions in central France (Cochard et al. 2004) and similar to the $d_{\max }$ of Scots pine trees growing in Belgium in soil with low levels of magnesium and phosphorus and high levels of nitrogen (Neirynck et al. 2008; Gebauer et al. 2015). The $T_{\text {num }}$ in control needles $(\sim 110)$ also resembled that for Scots pine trees growing in nutrient-imbalanced soil in Belgium (Gebauer et al. 2015), but was substantially lower for needles 411 DAG. These lower tracheid dimensions and numbers may have been the result of drought stress that occurred in spring at the beginning of needle development. While total precipitation for 2014 was above normal, these rain events were not evenly distributed throughout the season. Lower precipitation (69\% of normal) occurred in winter and spring, from January to June, which resulted in soil drought conditions at the study site (Supplementary Figure S1, Fajstavr et al. 2017).

\section{Conclusions}

The anatomical parameters of Scots pine needles were affected both by summer and winter girdling. The date of girdling and time elapsed after girdling were important factors in how the hydraulic parameters of needles were affected. Needles which were sampled 227 days after girdling (DAG) were girdled in winter, and therefore, their basic structure was already present in buds which were formed in the summer of the previous year. Tracheid lumen area, theoretical needle hydraulic conductivity, and xylem-specific hydraulic conductivity were by 18,39 , and $28 \%$, respectively, larger in needles 227 DAG than in control needles. Nevertheless, xylem area of needle and number of tracheids per needle 
227 DAG were similar to control needles. Thus, hypothesis 2 was only partially supported. In contrast, trees girdled in summer (July) and sampled 411 DAG developed their buds after girdling. Moreover, 411 DAG provided enough time to deplete carbohydrate reserves in the roots. It corresponded with very low transpiration rates measured in trees 411 DAG compared to control trees. Therefore, total tracheid lumen area per needle, xylem area of the needle, theoretical needle hydraulic conductivity, and number of tracheids per needle in trees 411 DAG were by $48,42,56$, and $39 \%$ smaller than in control needles. Nevertheless, tracheid dimensions 411 DAG were similar to control needles. Thus, hypothesis 3 was only partially supported. Girdling changed the internal balance during the development of needle xylem and phloem. We identified 16 correlations between the studied needle parameters in control trees, 11 in the trees 221 DAG, and 21 in trees 411 DAG (hypothesis 1 was supported). Two empirical equations were constructed, which enabled theoretical needle hydraulic conductivity and number of tracheids per needle to be calculated from an easily measurable xylem area of the needle. These equations could be useful tools for understanding whole-tree hydraulic architecture, as needles represent a disproportionately large fraction of the wholeplant hydraulic resistance (Nardini and Salleo 2000; Sack and Holbrook 2006). Understanding of this balance between various needle parameters will help us to understand mechanisms of regulation of stomatal conductance, photosynthesis, and transpiration.

Acknowledgements This work was funded by Czech project MSMT COST LD 13017 under the framework of the COST Action FP1106 network STReESS, Mendel University (Grant IGA 73/2013) and by the project "Indicators of Tree Vitality" (Reg. No. CZ.1.07/2.3.00/20.0265) co-financed by the European Social Fund and the Czech Republic. The authors declare no conflicts of interest.

\section{References}

Aulen G (1991) Increasing insect abundance by killing deciduous trees: a method of improving the food situation for endangered woodpeckers. Holarct Ecol 14:68-80

Baldwin HI (1934) Some physiological effects of girdling northern hardwoods. Bull Torrey Bot Club 61:249-257

Bongard-Pierce DK, Evans MMS, Poethig RS (1996) Heteroblastic features of leaf anatomy in maize and their genetic regulation. Int J Plant Sci 157:331-340

Čermák J, Deml M, Penka M (1973) A new method of sap flow rate determination in trees. Biol Plant 15:171-178

Cernusak LA, Marshall JD (2001) Responses of foliar $\delta^{13} \mathrm{C}$, gas exchange and leaf morphology to reduced hydraulic conductivity in Pinus monticola branches. Tree Physiol 21:1215-1222

Charra-Vaskou K, Mayr S (2011) The hydraulic conductivity of the xylem in conifer needles (Picea abies and Pinus mugo). J Exp Bot 62:4383-4390

Charra-Vaskou K, Badel E, Burlett R, Cochard H, Delzon S, Mayr S (2012) Hydraulic efficiency and safety of vascular and non-vascular components in Pinus pinaster leaves. Tree Physiol 32:1161-1170

Cochard H, Froux F, Mayr S, Coutand C (2004) Xylem wall collapse in water-stressed pine needles. Plant Physiol 134:401-408

Cruiziat P, Cochard H, Améglio T (2002) Hydraulic architecture of trees: main concepts and results. Ann For Sci 59:723-725

Dale JE (1988) The control of leaf expansion. Annu Rev Plant Physiol Plant Mol Biol 39:267-295

De Schepper V, Steppe K (2011) Tree girdling responses simulated by a water and carbon transport model. Ann Bot-Lond 108:1147-1154

Domec JC, Pruyn ML (2008) Bole girdling affects metabolic properties and root, trunk and branch hydraulics of young ponderosa pine trees. Tree Physiol 28:1493-1504

Ewers BE, Oren R, Kim H et al (2007) Effects of hydraulic architecture and spatial variation in light on mean stomatal conductance of tree branches. Plant Cell Environ 30:483-496

Fajstavr M, Vavrcik H, Gryc V, Giagli K, Urban J (2017) Stem girdling stress effect on Scots pine: above and below girdled area cell differentiation process. Silva Fennica (accepted)

Froux F, Huc R, Ducrey M, Dreyer E (2002) Xylem hydraulic efficiency versus vulnerability in seedlings of four contrasting Mediterranean tree species (Cedrus atlantica, Cupressus sempervirens, Pinus halepensis and Pinus nigra). Ann For Sci 59:409-418

Gebauer R, Čermák J, Plichta R, Spinlerová Z, Urban J, Volařík D, Ceulemans R (2015) Within canopy variation in needle morphology and anatomy of vascular tissues in a sparse Scots pine forest. Trees-Struct Funct 29:1447-1457

Hacke UG, Sperry JS, Pittermann J (2005) Efficiency versus safety tradeoffs for water conduction in angiosperm vessels versus gymnosperm tracheids. In: Holbrook NM, Zwieniecki MA (eds) Vascular transport in plants. Elsevier Academic Press, New York, pp 333-354

Hartmann H, Ziegler W, Kolle O, Trumbore S (2013a) Thirst beats hunger-declining hydration during drought prevents carbon starvation in Norway spruce saplings. New Phytol 200:340-349

Hartmann H, Ziegler W, Trumbore S (2013b) Lethal drought leads to reduction in nonstructural carbohydrates in Norway spruce tree roots but not in the canopy. Funct Ecol 27:413-427

Kawade K, Horiguchi G, Usami T, Hirai MY, Tsukaya H (2013) ANGUSTIFOLIA3 signaling coordinates proliferation between clonally distinct cells in leaves. Curr Biol 23:788-792

Kučera J, Čermák J, Penka M (1977) Improved thermal method of continual recording the transpiration flow rate dynamics. Biol Plant 19:413-420

Kučera J, Brito P, Jiménez MS, Urban J (2017) Direct Penman-Monteith parameterization for estimating stomatal conductance and modeling sap flow. Trees 31:873-885

López R, Brossa R, Gil L, Pita P (2015) Stem girdling evidences a trade-off between cambial activity and sprouting and dramatically reduces plant transpiration due to feedback inhibition of photosynthesis and hormone signaling. Front Plant Sci 6:285

Martre P, Durand JL, Cochard H (2000) Changes in axial hydraulic conductivity along elongating leaf blades in relation to xylem maturation in tall feste. New Phytol 146:235-247

Maunoury-Danger F, Fresneau C, Eglin T, Berveiller D, François C, Lelarge-Trouverie C, Damesin C (2010) Impact of carbohydrate supply on stem growth, wood and respired $\mathrm{CO}_{2} \delta^{13} \mathrm{C}$ : assessment by experimental girdling. Tree Physiol 30:818-830

McDowell NG (2011) Mechanisms linking drought, hydraulics, carbon metabolism, and vegetation mortality. Plant Physiol 155:1051-1059

Meinzer FC, Andrade JL, Goldstein G et al (1997) Control of transpiration from the upper canopy of a tropical forest: the role of stomatal, boundary layer and hydraulic architecture components. Plant Cell Environ 20:1242-1252 
Morgan JM (1984) Osmoregulation and water stress in higher plants. Annu Rev Plant Phys 35:299-319

Murakami PF, Schaberg PG, Shane JB (2008) Stem girdling manipulates leaf sugar concentrations and anthocyanin expression in sugar maple trees during autumn. Tree Physiol 28:1467-1473

Myers DA, Thomas RB, DeLucia EH (1999) Photosynthetic responses of loblolly pine (Pinus taeda) needles to experimental reduction in sink demand. Tree Physiol 19:235-242

Nardini A, Salleo S (2000) Limitation of stomatal conductance by hydraulic traits: sensing or preventing xylem cavitation? TreesStruct Funct 15:14-24

Nardini A, Salleo S, Andri S (2005) Circadian regulation of leaf hydraulic conductance in sunflower (Helianthus annuus L. cv Margot). Plant Cell Environ 28:750-759

Negreros-Castillo P, Hall RB (1994) Four methods for partial over story removal in tropical forests in Mexico. J Environ Manag 41:237-243

Neirynck J, Janssens IA, Roskams P, Quataert P, Verschelde P, Ceulemans R (2008) Nitrogen biogeochemistry of a mature Scots pine forest subjected to high nitrogen loads. Biogeochemistry 91:201-222

Pariona W, Fredericksen TS, Licona JC (2003) Tree girdling treatments for timber stand improvement in Bolivian tropical forests. J Trop For Sci 15:583-592

Phillips N, Oren R (1998) A comparison of daily representations of canopy conductance based on two conditional time-averaging methods and the dependence of daily conductance on environmental factors. Ann Sci For 55:217-235

Poorter H, Berkel YJV (2010) Soluble and insoluble sugars - extractions and chemical determinations. http://prometheuswiki. org/tiki-index.php?page $=$ Soluble + and + insoluble + sugars ++extractions+and+chemical. Accessed 10 Oct 2017

Poyatos R, Martínez-Vilalta J, Čermák J, Ceulemans R, Granier A, Irvine J, Köstner B, Lagergren F, Meiresonne L, Nadezhdina $\mathrm{N}$ et al (2007) Plasticity in hydraulic architecture of Scots pine across Eurasia. Oecologia 153:245-259

R Core Team (2015) R: a language and environment for statistical computing. R Foundation for Statistical Computing, Vienna, Austria. http://www.R-project.org/

Rawlinson H, Dickinson N, Nolan P, Putwain P (2004) Woodland establishment on closed old-style landfill sites in N.W. England. For Ecol Manag 202:265-280

Rivas F, Gravina A, Agusti M (2007) Girdling effects on fruit set and quantum yield efficiency of PSII in two Citrus cultivars. Tree Physiol 27:527-535
Sack L, Holbrook NM (2006) Leaf hydraulics. Annu Rev Plant Biol 57:361-381

Sellin A, Niglas A, Õunapuu E, Karusion A (2013) Impact of phloem girdling on leaf gas exchange and hydraulic conductance in hybrid aspen. Biol Plant 57:531-539

Setter TL, Brun WA, Brenner ML (1980) Effect of obstructed translocation of leaf abscisic acid on associated stomatal closure and photosynthesis decline. Plant Physiol 65:1111-1115

Sperry JS, Hacke UG, Pittermann J (2006) Size and function in conifer tracheids and angiosperm vessels. Am J Bot 93:1490-1500

Taylor A, Cooper P (2002) The effect of stem girdling on wood quality. Wood Fiber Sci 34:212-220

Tyree MT, Ewers FW (1991) The hydraulic architecture of trees and other woody plants. New Phytol 119:345-360

Tyree MT, Zimmermann MH (2002) Xylem structure and the ascent of sap, 2nd edn. Springer, Berlin

Urban L, Alphonsout L (2007) Girdling decreases photosynthetic electron fluxes and induces sustained photoprotection in mango leaves. Tree Physiol 27:345-352

Weaver RJ, McCune SB (1959) Girdling: its relation to carbohydrate nutrition and development of Thompson Seedless, Red Malaga and Ribier grapes. Hilgardia 28:421-456

Williams LE, Retzlaff WA, Yang WG, Biscay PJ, Ebisuda N (2000) Effect of girdling on leaf gas exchange, water status, and nonstructural carbohydrates of field-grown Vitis vinifera L. (cv. Flame Seedless). Am J Enol Vitic 51:49-54

Wilson BF, Gartner BL (2002) Effects of phloem girdling in conifers on apical control of branches, growth allocation and air in wood. Tree Physiol 22:347-353

Yan CF, Han SJ, Zhou YM, Wang CG, Dai GH, Xiao WF, Li MH (2012) Needle-age related variability in nitrogen, mobile carbohydrates, and $\delta{ }^{13} \mathrm{C}$ within Pinus koraiensis tree crown. PLoS ONE 7:e35076

Yang SD, Tyree MT (1994) Hydraulic architecture of Acer saccharum and $A$. rubrum: comparison of branches to whole trees and the contribution of leaves to hydraulic resistance. J Exp Bot 45:179-186

Zhao K, Tung CW, Eizenga GC, Wright MH, Ali ML, Price AH, Norton GJ, Islam MR, Reynolds A, Mezey J et al (2011) Genome wide association mapping reveals a rich genetic architecture of complex traits in Oryza sativa. Nat Commun 2:467

Zuur AF, Ieno EN, Walker N, Saveliev AA, Smith GM (2009) Mixed effects models and extensions in ecology with R. Springer, New York 